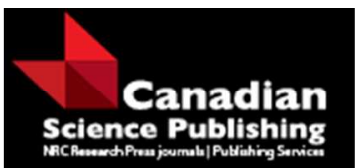

Canadian Journal of Forest Research

Revue canadienne de recherche forestière

\title{
A new method for capturing stem taper variation for trees of diverse morphological types
}

\begin{tabular}{|r|l|}
\hline Journal: & Canadian Journal of Forest Research \\
\hline Manuscript ID & cjfr-2016-0018.R1 \\
\hline Manuscript Type: & Article \\
\hline Date Submitted by the Author: & 18-Mar-2016 \\
\hline Complete List of Authors: & $\begin{array}{l}\text { MacFarlane, David; Michigan State University } \\
\text { Weiskittel, Aaron; University of Maine }\end{array}$ \\
\hline Keyword: & taper, form, branching architecture, mixed-effects modeling, morphology \\
\hline
\end{tabular}

SCHOLARONE $^{\text {tu }}$
Manuscripts 
1 A new method for capturing stem taper variation for trees of diverse morphological types.

2 David W. MacFarlane ${ }^{1^{*}}$ and Aaron R. Weiskittel ${ }^{2}$

$3{ }^{1}$ Department of Forestry, Michigan State University, East Lansing Michigan, 48840

$4 \quad{ }^{2}$ University of Maine, School of Forest Resources, Orono, ME 04469

$5 \quad{ }^{*}$ corresponding author; email: macfar24@msu.edu

6 Abstract

7 Understanding variation in tree stem form is fundamental to both ecological and economic 8 assessments of forest ecosystem structure and function. Stem taper models (STMs) are widely 9 used to describe tree form, but it can be challenging to apply them to trees with stems that 10 diverge from an idealized norm, often leading to exclusion of many trees from stem taper 11 studies. Here, new 'whole-tree' form type classes are advanced, as simple and useful

12 groupings for capturing stem form variation of trees of diverse morphological types, and tested 13 with a large tree data set without exclusion criteria. New form type classes explained much 14 more of main stem form variation than knowledge of tree species, while 'merchantable form 15 types' explained most stand-to-stand level variation. Broad-leaved species were much more 16 likely to have complex stem forms than needle-leaved, but species 'evergreeness' was a very 17 weak predictor of stem form variation, when tree and stand -level form variation was accounted 18 for. A new, generalized framework for stem taper modeling is demonstrated, using both species and merchantable form types to capture tree-level random effects. New form types and the STM approach are relatively easy to apply and should be relatively simple to integrate into any

21 conventional forest inventory system. Overall, the study demonstrates the importance of

22 including and accounting for the diversity of observed stem forms in developing STMs.

23 Keywords: taper, form, branching architecture, mixed-effects modeling, morphology 


\section{Introduction}

Stem taper models (STMs) describe the changing shape of the 'main' stem of a tree, from ground to tree top. This enables them to be used to explore and predict variation in stem morphology for trees of diverse species, because stem taper reflects factors such as ecological conditions and forest management history (Assmann 1970, Muhairwe et al. 1994, Niklas 1995, Valentine and Gregoire, 2001, Bravo-Oviedo et al. 2014). STMs have long been applied to forest inventory data, because they allow for estimation of merchantable stem volume to a variable top diameter as well as merchandizing the stem into various products (Kozak et al. 1969). More recently, they have been applied to simultaneously estimate tree volume and biomass (Jordan et al. 2006, Zakrzewski and Duchesne 2012, Ver Planck and MacFarlane 2015), which can allow for extension of timber volume inventories to ecological studies and provide quantitative data for understanding synergies and tradeoffs between different types of forest ecosystem services, such as carbon storage versus timber production. For example, the US Forest Inventory and Analysis program currently links national timber stocks inventory data tree's merchantable main stem volume. be challenging to apply them to trees with complex stem forms, namely trees that fork to some significant degree or have major limbs that otherwise distort the idealized, continuous main stem MacFarlane (2014) showed that taper may drop precipitously at branch nodes, especially if the branches are large relative to the main stem. Tree modelers have taken two general approaches to address this challenge: (1) exclude trees which do not conform well to the assumed model, or (2) incorporate different tree branching architectures into STMs. 
The prevailing approach is to fit STMs to a sample population of trees that have been

50

51

52

censored to some degree by excluding trees which diverge from some idealized stem form. Many research papers report excluding 'irregular' trees from data sets used to fit STMs. For example, Burkhart (1977) reported including only single-stemmed trees, while others excluded trees with forks (Forslund 1982, Barrio Anta et al. 2007) or trees with multiple stems or crooked boles (Özçelik 2008). McTauge and Bailey (1987) excluded trees with forks, ramicorn branches (large, high-angled branches) or 'foxtails' (sections of the stem which grow without producing any lateral branches) and Newnham (1992) reported excluding 2293 of 7367 (31\% of) trees, which had 'defects', when fitting taper models to four Alberta tree species, without specifying what those defects were. Sometimes, entire types of stands have been excluded from STM studies. For example, Burkhart and Walton (1985) chose plantations that had not been thinned, burned, or pruned, and were free of severe insect or disease damage, to assess the influence of crown variation on the taper of loblolly pine (Pinus taeda L.). Such censoring could be a significant problem whenever STMs fit to censored data are later applied to populations of trees covering a larger range of tree forms or stand conditions, which is generally the case.

Some researchers have sought approaches which recognize that a model of the main stem of a tree should be referenced somehow to the whole tree it is part of, whose other parts (namely branches) influence its form (MacFarlane 2010, Ver Planck and MacFarlane 2014). Muhairwe (1994) demonstrated that simply including a measure of crown size as a predictor variable could help explain some of the variation in tree shape, in even-aged, fully-stocked, lodgepole pine (Pinus contorta) stands, where we would expect fairly uniform crown geometry. One solution offered for teak (Tectona grandis) explicitly parameterized the heights of forks and the relative change in diameter at forking points into the STM (Adu-Bredu et al. 2008). While effective, this latter model requires a number of additional measurements on every tree, which would be time consuming and prone to measurement error, and the model allows for only two 
74 forks in a tree. Two other approaches model continuous shifting allocation between a main stem 75 and branches, above and below a relative crown height, but require some prior estimate of 76 volume (Ver Planck and MacFarlane 2014) or the centroid of volume (MacFarlane 2010) for 77 each tree. Zakrzewksi (2011) modeled the cumulative distribution of volume from a taper 78 model, including wood in both the main stem and branches, but his approach did not allow for 79 separation of main stem volume from branch volume; the two components were treated as a 80 composite sum.

Our literature review revealed that, despite a long history of applying STMs in forestry and recent efforts to link changes in tree form to changes in tree biomass and forest carbon storage (e.g., Chave et al. 2014, MacFarlane 2015), little research has been conducted to document the potential problem of excluding trees with diverse forms, when fitting STMs.

85 Further, no generalized, low-cost, simply-to-apply solution has been advanced to model stem 86 taper over the very broad range of tree forms that can be observed. A simple, and possibly 87 effective approach would be to identify 'whole-tree' form types (meaning ones that reference 88 both the main stem and branches), which trees could be relatively easily assigned to and would 89 capture major differences in main stem form variation, with specific reference to the relative 90 'branchiness' of the tree. To address these issues, we: (1) develop whole-tree form type 91 classes that provide useful groupings for capturing stem form variation; (2) assess the relative

92 abundance of trees of different form type classes, within and between species, from a large tree 93 data set with no specific exclusion criteria; (3) explore the hierarchical structure of variation in 94 tree form at the tree, stand and species levels over a large spatial domain, and (4) discuss 95 implications of the former on development and application of STMs to trees of diverse stem form 96 and branching architecture. 


\section{Materials and Methods}

\subsection{Study area and tree data}

The study area included public forest lands in the state of Michigan, USA. These forests cover about 1.7 million ha of Michigan's 14.7 million ha land area and encompass a diverse array of glacial landforms and forest community types, within temperate broad-leaf and mixed needle-leaf-broad-leaf biomes (Dickmann, 2004). Stands were selected at 31 test locations to cover a diverse set of species, tree sizes and stand conditions and involved all Michigan Department of Natural Resources (MDNR) management regions across the state. Trees were selected from 12 of the locations using horizontal point sampling on a $64 \mathrm{~m}$ square grid. At the other 19 locations, trees were selected systematically, sequentially selecting sample trees of desired species within size classes, until the desired size range of target species were sampled from the stand. In all cases, trees were selected without exclusion of trees with complex or irregular stem forms. In total, 1828 trees of 21 species were destructively sampled covering a wide range of sizes, from a minimum size of $11.7 \mathrm{~cm}$ to a maximum of $101.6 \mathrm{~cm}$ diameter at breast height (DBH; $1.3 \mathrm{~m})$ (Table 1).

Trees were felled and dissected by professional loggers and measured. Stem diameter at breast height $(\mathrm{DBH}, \mathrm{cm})$ was measured before felling and total height $(\mathrm{H}, \mathrm{m})$ was measured after felling (species averages are shown in Table 1). The main stem and branches of each tree were cut into approximately $2.5 \mathrm{~m}$ sections to a $10 \mathrm{~cm}$ top diameter outside bark (DOB), although shorter and longer section lengths were occasionally included. Beginning with the stump, the main stem diameter outside bark was measured at the ends of cut sections along with the length of each section all the way to the top of the tree. The main stem was followed to the top of the tree, selecting the largest and most vertical stem at a fork to be the main stem (aka the "dominant" stem, sensu VerPlanck and MacFarlane 2014). Any branch with a basal 
122 diameter of at least $10 \mathrm{~cm}$ with at least $2.5 \mathrm{~m}$ long, sound section was measured to a $10 \mathrm{~cm}$ top

$123 \mathrm{DOB}$, in the same manner as the main stem.

124

125

126

127

128

129

130

131

132

133

134

135

136

137

138

139

140

141

142

143

144

\subsection{Whole-tree form types defined}

Botanists have worked for decades to define generalized architectural models for plant form, based on the relative arrangement of plant parts, which reflect both endogenous (genetic) and exogenous (environmental) processes that define plant form at any point in time (Barthélémy and Caraglio 2007). Here, we sought to define analogous architectural form types for trees, to capture major, visually-apparent differences in the allocation of wood to the main stem versus branches. The form classes were also designed to be consistent with common forest inventory practices, to give them practical as well as scientific value for tree form evaluation.

\subsubsection{Large Branch Type (LBTs)}

MacFarlane (2010) theorized that only relatively large branches should have a significant impact on main stem form, so the simplest classification is binary, determining whether a tree has relatively large branches, or not. This Large Branch Type (LBT) takes on a value of zero if the tree has no large branches and a value of one if it does. The definition of a 'large' branch may vary from region to region, but can be made consistent within a forest inventory system by linking it to merchantability standards applied within that system. Here, the minimum size of a 'large' branch is one with a minimum basal diameter $=10 \mathrm{~cm}$ and containing at least one sound, pulp-sized log to a minimum top $\mathrm{DOB}=10 \mathrm{~cm}$. This standard meets the average minimum specifications for a merchantable section of a tree in Michigan forestry practices (MDNR 2013) and the USA in general (e.g., Clark et al. 1991, Jenkins et al. 2003, Woodall et al 2011). For this study, trees were assigned an LBT = 1 if they contain a branch with at least $2.5 \mathrm{~m}$ long 
145 branch section, with a minimum basal diameter of $10 \mathrm{~cm}$ and a minimum top DOB also = 10; or $146 \mathrm{LBT}=0$, otherwise. All study trees were assigned an LBT (see Table 2).

The LBT can be made more descriptive and useful for volume inventory by

149 differentiating between large and very large branches, which can correspond in size to branches

150 that could be used for the two major types of wood products: pulp and saw products,

151 respectively. To be classed as having branch saw wood present, a tree needed to have at least

152 one branch section at least $2.5 \mathrm{~m}$ long, with a minimum basal diameter $=20 \mathrm{~cm}$ and at least one

153 sound log to a minimum top $\mathrm{DOB}$ also $=20 \mathrm{~cm}$; this is also consistent with regionally and

154 nationally -used minimum merchantability standards cited above. Trees are assigned to MBTs

155 using a two-digit code system, with the first digit representing the absence / presence of pulp

156 log-sized branches and the second indicting the absence / presence of saw log-sized branch

157 sections. So, there are four possible MBTs for a tree: 0-0 = no merchantable branch wood; 1-0

158 = pulp wood in branches, but no saw wood in branches; $0-1=$ no pulp wood in branches, but 159 saw wood in branches; and 1-1 both pulp and saw wood in branches. All study trees were 160 assigned an MBT (see Table 2).

\subsubsection{Merchantable Form Types (MFTs)}

LBTs and MBTs allow for identification of trees with or without large, merchantable

163 branches, or of different branch types, but have no code representing the main stem. Since

164 trunk taper is expected to change as a tree increases in size (Niklas 1995), form types can be

165 further differentiated by categorizing the main stem into two merchantable types, just as the 166 branches were under the MBT system. So, a four-digit Merchantable Form Types (MFT) code

167 was developed to create a variety of tree form types relevant to forest inventory methods, depending on whether or not the tree contains merchantable wood in some or all of the 
169 following four categories: (1) main stem pulp, (2) main stem saw, (3) branch pulp, or (4) branch

170 saw. A value of " 1 " is recorded when that part-product is present and " 0 " when it is not. So, a

171 tree with a code of "1-0-1-0", would have pulp wood volume in both the main stem and

172 branches, but would not have any saw wood volume in either tree component. All study trees

173 were assigned an MFT (see Table 3).

174 2.3. Analytical Methods

Our data set consisted of measurements of the change in main stem cross-sectional area, as a function of height above ground from the stump to the top of the tree, computed from

177 the stem diameter measurements taken along the stem. We used a multi-level mixed-effects

178 modeling framework for analysis (Venables and Ripley 2002), recognizing the hierarchical

179 structure of our data, where correlated within-tree variation in stem cross-sectional area

180 (computed from the stem diameter measurements of the stem) represented the finest level of

181 variation. When specifying the hierarchy, we sought to investigate tree-level form variation from

182 the most general to the most specific effects on tree form, which was, from top to bottom:

183 evergreeness $>$ spp $>$ form type $>$ stand $>$ tree. Since genetics has a top-down effect 184 constraining tree form (Barthélémy and Caraglio 2007, Dardick et al. 2013), 'evergreeness'

185 (e.g., Ducey 2012) was used as a the coarsest group, which species were nested in, reflecting 186 the expected difference between trees with a decurrent (broadleaf) versus excurrent (needle187 leaf) stem form due to expected differences in apical dominance between conifers and 188 angiosperms (Wilson 2000). Species-level effects were further refined by form type groupings 189 (LBT, MBT, MFT), which represented within-species variation in form. Finally, the random effect 190 of local environment on tree form (Xiong et. al. 2010) was captured by the specific stand 191 conditions the trees were drawn from. 
In our first analytical step, we computed main stem volume for each tree from the taper measurements using tree-specific mixed-effects B-spline regression; a semi-parametric method 194 described by Kublin et al. (2013), that was fit using the TapeR package (Kublin and 195 Breidenbach 2013) in R v3.2.3 (R Core Team 2015). Then, we estimated the relative 196 contribution of each grouping variable in the hierarchy to stem form variation, using main stem 197 volume as an integrating variable to capture stem form differences. This was accomplished with 198 the varcomp function within the APE package (Paradis et al. 2004) in $\mathrm{R}$, which computes the 199 variance components from a fitted mixed-effects model object.

Our next step was to use non-linear mixed effects modeling ( $n / m e$, Venables and Ripley

201 2002) to fit a parametric taper model to the whole data set (all trees) and then adjust model

202 coefficients based on random effects, which were allowed to vary based on how each individual 203 tree diverged from the trend over all the diverse tree types represented in our data. There were 204 several reasons for this approach. First, there was insufficient data to fit a separate model for 205 every combination of species and form type, despite the very large data set we had (see Tables 2062 and 3). A combined model with dummy variables for each species and form type would have 207 created an enormous number of parameters and coefficients to estimate; even a reduced 208 version with only evergreeness and LBT failed to converge on a solution. Simply allowing the 209 intercept to vary by species or form type resulted in grossly oversimplified effects of form type or 210 species.

We chose the highly flexible segmented polynomial model of Max and Burkhart (1976) to 212 explore how well the form types captured major differences in tree form, within and between 213 species, because this model is well-tested, it has been previously been shown to work with 214 predicted random effects (Cao and Wang 2011), and allowed for evaluating the influence of tree 215 form on various stem segments. 
$217 Y=\beta_{1}(X-1)+\beta_{2}\left(X^{2}-1\right)+\beta_{3}\left(\alpha_{1}-X\right)^{2} I_{1}+\beta_{4}\left(\alpha_{2}-X\right)^{2} I_{2}$

eq. 1

218 where $Y$ is the relative squared diameter outside bark $\left(d^{2}, \mathrm{~cm}^{2}\right)$ at a height above ground $h(\mathrm{~m})=$

$219\left(d_{h} / D B H\right)^{2}$, which hereafter is referred to as relative cross-sectional area outside bark (relcob); $X$

220 is the relative height above ground $(r e l h)=h / H$; and $\alpha_{i}$ and $\beta_{i}$ are coefficients to be estimated,

221 with $\alpha_{i}$ representing the joining points of the segments of the equation. $I_{1}$ and $I_{2}$ are indicator

222 variables denoting the relative position of the joints with respect to the $t^{\text {th }}$ cross-sectional position

223 in the upper and bottom portions of the tree, respectively.

$I_{2}=1$, if $\alpha_{2} \geq X$, else $I_{2}=0$.

Max and Burkhart (1976) allow for $\alpha_{i}$ to be specified or estimated as free coefficients.

We tested a model where we set the value of $\alpha_{2}$ at the relative height of $\mathrm{DBH}(\overline{r b h})$, because this simplified model fitting procedures, and because $\alpha_{2}$ is typically very close to $\overline{r b h}$ point when estimated independently ( $\alpha_{1}$ by contrast is highly variable, typically occurring somewhere between 50 to $90 \%$ of total tree height). Additionally, since the general form of the taper model

231 (eq. 1) is relative to $\mathrm{DBH}$ there is a natural inflection point at $\mathrm{DBH}$, where $\mathrm{Y}=1$; points below 232 that are generally $Y>1$ and above that $Y<1$.

$$
I_{1}=1 \text {, if } \alpha_{1} \geq \mathrm{X}, \text { else } I_{1}=0
$$

$$
I_{2}=1 \text {, if } \overline{r b h} \geq \mathrm{X} \text {, else } I_{2}=0
$$


237 We fit both models (eq. 1 and eq. 2) to the data and used a likelihood ratio test to determine if 238 leaving $\alpha_{2}$ as a free coefficient was superior to assigning it to $\overline{r b h}$.

To fit the models above, we used the NLME package (Bates et al. 2015) in $\mathrm{R}$, specifying tree-level random effects nested within each stand. In addition, hierarchical data tend to have within-subject correlation and are also likely to have within subject residual heteroscedasticity.

242 We dealt with both by inclusion of a continuous first-order autoregressive (CorCAR1) correlation 243 structure and a variance power (varPower) weighting structure as a both function of relative 244 height to address within-subject correlation and heteroscedasticity, respectively. However, both 245 were found to not significantly improve model fit (tested using a likelihood ratio comparison) and consequently, not included in the final model.

We explored different combinations of model coefficients $\alpha_{i}$ and $\beta_{i}$ as random effects to determine which was contributing the most to unexplained variation. We looked for the best

249 combination of coefficients to assign random effects to, which allowed models to converge and 250 which improve the model fit as indicated by a likelihood ratio test. In the final stage of modeling, 251 we predicted the random effects for each tree within each stand from the best model, as linear 252 functions of species and form types.

\section{Results}

\subsection{Diversity in tree form types}

A broad range of tree form types were found within and among species over a range of

257 tree sizes (Tables 2 and 3). As expected most needle-leaf trees had few branches large 258 enough to meet minimum merchantability standards (only $3 \%$ of trees examined had an LBT =

259 1, Table 2). Pinus strobus, however, was the exception among conifers, with about $14 \%$ 
260

261

262

263

264

265

266

267

268

269

270

271

272

273

274

275

276

277

278

279

280

281

282

283

containing large branches (Table 3). By contrast, almost half of all broad-leaved trees we observed had at least one large, merchantable branch and about $17 \%$ of those were large enough to produce saw logs (Table 2).

Over all trees, the five most common MFTs were: 1-0-0-0: which corresponds roughly to smaller ("pole"-sized) trees (smallest DBH = $12 \mathrm{~cm}$ ) without relatively large branches; 1-0-1-0: smaller trees $(\mathrm{DBH} \geq 15 \mathrm{~cm}$ ) with a major fork; 1-1-0-0: larger (saw-timber-sized trees without large branches, smallest with $\mathrm{DBH}=21 \mathrm{~cm}) ; 1-1-1-0$ : larger trees with large branches $(\mathrm{DBH} \geq$ $21 \mathrm{~cm}$ ); and 1-1-1-1: large trees with saw-log sized branches (smallest individual had DBH = 31 $\mathrm{cm})$. Allometrically, a tree has to be large enough to grow a relatively large branch, and the bigger the ratio of the largest branch to the main stem, the more dramatic the fork (MacFarlane 2010). For example, the smallest tree with a pulp-sized branch (category 1-0-1-0) had a branch fork with a basal diameter almost as large as the main stem.

\subsection{The relative contribution of form types to explaining tree form variation}

Analysis of variance components of main stem volume showed that knowing the species or species group ('evergreenness') explained very little of the difference in main stem form and volume, when compared to tree-to-tree and within-stand variation, suggesting a very high level of intra-specific variation in stem form, across a broad range of species and forest communities (Fig. 1a). Knowing that a tree, within a species, has a relatively large branch (LBT), large enough to be merchantable, added considerably to explaining tree to tree variation (Fig. 1b). Furthermore, including information related to the saw timber potential of the branch (MBT), increased the degree of variation explained (Fig. 1b). MFTs were the most informative; knowing the MFT of a tree explained about half of the tree-to-tree variation in main stem volume, but it also helped considerably to clarify intra-specific variation, such that they combine to explain about two-thirds of within-tree form variability (Fig. 1d). Further, with trees assigned to a MFT 
284 much of the variation between stands was accounted for (note the relatively shallow slope from 285 'MFT' to 'stand' in Fig. 1d, relative to that for species, LBT and MBT, Fig.1 a-c, respectively).

3.3. Divergence of trees of different form type and species from a general all-species STM

The DBH-segmented Max and Burkhart (1976) model (eq. 2) was superior by all metrics to the standard model (eq. 1, Table 4), so it was used for all subsequent model fittings. Only having to estimate one joining point simplified estimation of fixed and random effects on other model coefficients. The best model that converged was one with random effects on coefficients

$291 \beta_{1}, \beta_{2}$, and $\beta_{4}$, as indicated by AIC, BIC, and a likelihood ratio test (Table 5). Both MFT and species were significantly $(p<0.0001)$ and linearly correlated with all three coefficients and model fitting generated using linear adjustment factors for each coefficient depending on the species and MFT (Table 6).

$$
I_{1}=1 \text {, if } \alpha_{1} \geq \mathrm{X} \text {, else } I_{1}=0
$$

where $\mu_{1(i j k)}, \mu_{2(i j k)}$, and $\mu_{4(i j k)}$ are the predicted random effects for a tree in stand $k$ of MFT $j$ and species $i$. Coefficients and fit statistics for eq. 3 area shown in Table 6.

After fitting, eq. 3 was used to explore model behavior. To apply the model, stand-level 302 random effects were set to zero and the predicted random effects terms for both MFT and 303 species were added to the random effects intercepts which were then added to the fixed effects 304 terms in the models (Table 6). 
For example, the predicted random effect term $\mu_{1}$ was added to the fixed effect coefficient $\beta_{1}$ (eq. 3). The intercept for the predicted random effect $=0.0710$ (Table 6$)$. If the tree was an Acer saccharum tree with a MFT of 1-0-1-0 we added - 0.1606 (for species, Table 6) plus -0.1714 (for MFT, Table 6), meaning $\mu_{1}=0.0710+[-0.1606]+[-0.1714]=-0.3320$, which is added to the fixed-effect coefficient $\beta_{1}(=-3.9845$, Table 6$)+[-0.3320]=-4.3165$.

Looking at form variation within a species, against the background of variation in all species (Fig. 2), it can be seen that e.g., Q. rubra trees with relatively large branches had considerably more taper than Q. rubra trees without them, such that saw-sized trees with sawsized branches (MFT = 1-1-1-1) were more similar in stem form to pole-sized trees with polesized branches $(1-0-1-0)$ than the latter were to pole-sized trees without large branches (1-0-00). Comparing two species, e.g., A. saccharum and T. americana, which tend to co-occur on a variety of mesic upland sites in the region, we can see a case where species differences were important, but only in magnifying differences caused by branching (Fig. 3). According to our model (eq. 3) and the underlying data (see Fig. 3), the main stem of T. Americana tends to taper less than that of sugar maple, on average, even when forks or other major branching effects are accounted for. However, the "regular" form stems (1-0-0-0) of both species are more similar to each other than "forked" individuals (1-0-1-0) of the same species, further demonstrating that intraspecific stem form variation tended to be much greater than interspecific variation (as shown in Fig. 1). The model (eq. 3) clearly shows that the net effect of branching is to divert volume from the main stem into branches, increasing stem taper and reducing accumulated volume in the main stem. 
329

330

331

332

333

334

335

336

337

338

339

340

341

342

343

344

345

\section{Discussion}

4.1. The value of form type classes which consider both stem and branches

Foresters have long recognized that trees have different stem forms and have sought ways to capture this, as a way to improve stem volume estimation, but also to fundamentally understand variability in tree form. For example, Assmann (1970) chronicled almost a century of theories which attempt to describe tree-to-tree stem form variation, and noted (on p. 64) "the problem of form and form factor", which is simply the fact that tree-to-tree stem form varies within wide limits and, for each tree, it responds dynamically to changing environments (e.g., thinning, see Assmann 1970, p. 61). Much of the early research on form resulted in the advent of 'form classes', which look at the ratio of some upper stem diameter, typically to top of the first log (e.g., Girard Form Class, Avery and Burkhart 2015) to DBH. These early form classes generally differ from modern STMs, because they focus mainly on modeling taper lower down in the tree's stem, where the most economically valuable parts are. Since STMs seek to profile stem form from the base to the top of the tree using a continuous mathematical function (Zakrzewski 1999), they should require more complex form type classifications, unless they are applied only to trees with regular form, where it might be reasonable to assume that form differences captured lower extend all the way to the top of the tree.

Here, we experimented with multiple new form-type classes, which recognize that the main stem is embedded in, and an inextricable part of, a complex tree branching network (Barthélémy and Caraglio 2007). Our results suggest that 'regular' stem form might even reflect a special case for many species. Again quoting Assmann's (1970) seminal text: "As compared with the many diverse and, in some cases, bizarre outlines of broad-leaved trees, conifers present regular forms." Our study generally supports Assmann's (1970) assertion, with a large amount of data collected over a range of species and forest conditions, although Pinus strobus 
353 appears to diverge considerably from the general pattern for conifers. This species is a mid-

354 tolerant conifer that often regenerates naturally under an intolerant hardwood canopy (Bebber et 355 al 2004) and tends to have excessive forking due to a white pine weevil (Pissodes strobe),

356 which kills terminal shoots and releases branches from apical dominance (Stiel 1979). Thus,

357 while observed differences between needle-leaved and broad-leaved, could be expected due to 358 coarse-level taxonomic differences in apical dominance (Wilson 2000), needle-leaved species

359 may not have regular form under natural forest conditions. For example, Xiong et. al. (2010)

360 showed that genetics is important in determining forking in Pinus taeda, but also that local

361 environmental / silvicultural factors tended to explain most of the forking variation. The other two

362 pine species we examined ( $P$. resinosa and $P$. banksiana) were drawn mainly from only a few

363 plantations, where spacing and density were kept more uniform during growth, so our data set 364 may actually underestimate how branchy pines are. Certainly, the fact that so many published 365 STM studies of needle-leaved species report excluding forking or branchy trees (e.g., McTauge and Bailey 1987), suggests that such trees are not uncommon in the general population.

Our study demonstrates that the new form type classes: LBT, MBT, and MFT, provide a highly useful system for capturing variation in stem form, within and between species, and MFTs appear to explain most of the variation caused by different stand / site conditions. MFTs offer the most flexible system for classifying trees, because they explicitly consider the size of both main stem and branches. Additionally, the MFT coding allows some unusual tree forms to be 372 specifically identified. For example, our data set also included some very large individuals of 373 Pinus strobus (up to $100 \mathrm{~cm} \mathrm{DBH}$ ), which had a unusual form type, MFT = 0-1-0-0, which 374 characterizes a tree with only saw-timber-sized sections of the main stem, which rises up to a 375 top that breaks into many small branches (Table 3). A STM would typically predict that a large 376 tree with saw timber lower in the stem, would also have pulp wood higher up in the main stem 377 above it. 
MFTs might also allow for the possibility of capturing trees with defects, with

consideration of the size of the tree. For, example a tree with a code of "0-0-0-0" could either be too small to meet merchantability requirements $(<10 \mathrm{~cm} \mathrm{DBH})$ or a large-enough tree (typically $\geq 12 \mathrm{~cm} \mathrm{DBH}$ by US standards), but with significant defects which limited the merchantability of the section. So, aside from helping to better predict stem volume these new form types can be used to better characterize form diversity in growing stock, which could be related to growth and mortality trends.

A potential problem with any classification system is misclassification, but the form type classes described here are easy to implement. In fact, the Michigan DNR already implements a more complex system in their forest volume inventory, in that foresters are already trained to count the number of saw and pulp logs in both the main stem and branches of trees (MDNR 2013). MFTs are a simplification, in that those log counts are reduced to a binary, presence or absence assessment for each category of wood products. Consequently, this classification system could be implemented right away in Michigan, USA and a similar system could likely be developed for any forest inventory system that encounters trees of diverse form. Even simpler are the MBT or LBT classes. They provide less information for differentiating trees, but may have lower misclassification error, but could be used in lieu of MFTs, if misclassification error were to outweigh gains of using a more complex form type.

One limitation of the form types presented here is that there is only one MFT that can accommodate trees smaller than $10 \mathrm{~cm} \mathrm{DBH:} \mathrm{0-0-0-0.} \mathrm{Previous} \mathrm{studies} \mathrm{have} \mathrm{suggested} \mathrm{that}$ small / young trees have different forms than mature trees (Niklas 1991, Ter-Mikaelian et al. 2004), but it should be acknowledged that small-tree form can be influenced by branching too. Kerr and Boswell (2001), e.g., surveyed regenerating forests across the United Kingdom and found that $69 \%$ of young Fraxinus excelsior trees had at least one fork and $29 \%$ had more than one. The level of forking varied widely from site to site and was hypothesized to be related to 
403

404

405

406

407

408

409

410

411

412

413

414

415

416

417

418

419

420

421

422

423

424

425

426

terminal bud damage from frost and bud moths. Kerr and Boswell (2001) also noted that such forks tend to persist, leading to a reduction in the saw timber volume produced in the lower stem of these trees later in life. So, clearly small trees can have complex forms that warrant more than a simple taper modeling approach and the form types of larger trees often reflect the evolution of form types set early in the life of the tree. In combination with other results, this highlights the potential benefits of a more generalized classification approach, where, e.g., branch size is expressed relative to the size of the main stem, instead of in absolute terms.

\subsection{Hierarchical structure of variation in tree form at the tree, stand and species levels}

Our data and analyses indicate that tree-to-tree variation in form is enormous over the wide range of species and stand conditions we examined. It was surprising how little 'evergreeness' and species mattered as grouping variables, in light of this variation. The practical implication is that if a tree is randomly drawn from the landscape and measured for stem form and volume, knowing whether it is a needle leaved vs. broad-leaved tree, or even its species, does not tell us much more about its form. By contrast, knowing the particular stand it was drawn from tells us quite a lot, because the ecological conditions and historic stand dynamics have an apparently large effect on how that tree grew. This supports the idea that species-specific volume models are not superior to 'composite' or mixed species ones, because so-called species effects are often confounded with effects of the stand conditions from which the species data were drawn; "taper is greatly influenced by the past history of the stand" (Gevorkiantz and Olsen 1955). Here, we used mixed effects modeling to disarticulate species and stand effects and used our new form types to capture growth-history effects at the individual tree level, which explained most of the stand-level influence on tree form.

Since MFTs did not capture all the stand-to-stand variation in stem form, our hierarchical analysis indicated other residual uncertainty from stand level factors. Stand density should 
427 affect taper to some degree and also act to reduce lateral branching when density is high

428 (Neilsen and Gerrand 1999). Garber and Maguire (2003) showed that including height-diameter

429 ratios as a model predictor could to some extent account for stand to stand variation in stem

430 taper, because it tends to be correlated with stand density and it is a good proxy for crown ratio,

431 at least in stands with simple crown architecture. However, they also concluded that spacing

432 had little appreciable influence on the taper of some species (e.g., Abies grandis) and

433 underscored the importance of developing site and species-specific equations. By contrast, our

434 goal was to reduce the need for stand / site specific equations. Muhairwe et al. (1994) explored

435 the explanatory power of site productivity class and age into STMs developed for several

436 species, but concluded that the variables contributed only marginally to improving the model.

437 Stand-to-stand / site-to-site variation in stem form may be confounded with other factors, such

438 as local genetic effects on taper (Sherill et al. 2004, Gomat et al. 2011), but we would expect

439 these to be evident in the form type and species combinations represented in the stand.

440 Ultimately, it simply may not be possible to explain all the stand-to-stand variation in tree form.

441 4.3. Implications for development and application of STMs to trees of diverse form and

442 branching architecture.

The results of this study suggest that STM approaches would benefit more from fitting

444 them by form type, then by species, but that it would be most useful to fit MFT-specific models

445 for every species. In terms of this study, that would mean filling a data matrix of trees covering

44621 species by 16 MFTs. Over even larger spatial domains, such as a national forest inventory,

447 fitting at set of form-by-species models would require an enormous data set, where trees with a

448 variety of non-regular forms were sought out. Such data sets are currently rare and will likely

449 remain so given the high cost of sampling for stem taper/volume. 
Instead of trying to fit a model for every combination of species and form type, we chose

451 to use a universal hierarchical modeling approach, which could draw from the strength of all our

452 data. This method also respects and accounts for within-tree and within-stand variation in taper

453 measurements, by treating them as deviation from the general population (i.e. random effects).

454 After accounting for this hierarchical variation, our universal model predicts how each tree

455 diverges from the all-tree trend, based on its species and MFT. This approach bears similarities

456 to the STM approach of Cao and Wang (2011), except that an actual stem measurement was

457 needed at the mid-point of the stem to localize the model for each tree under their approach.

458 Indeed, calibrating taper models in a mixed-effects modeling framework is a promising new

459 approach (Sabatia and Burkhart 2015), but often relies on upper stem diameter measurements

460 which can be difficult to measure accurately. Our approach, in a sense, estimates the random

461 divergence of members of a species from the all-species trend, but also independently captures

462 the average form deviation of a tree of any species, depending on a simple assignment of trees

463 to categories related to the relative size of the main stem and branches. This novel approach

464 appears to be quite effective for exploring intra- and inter-specific variation in stem form, but

465 likely needs more testing before it is implemented operationally for forest volume estimation.

466 Certainly, there appears to be an opportunity to further explore stand-level predictors of form,

467 with the opportunity to account for tree-level differences, captured by form type classes.

Another major implication of this study is that the exclusion of trees without 'regular' form

469 represents a significant omission from the STM literature, and also likely translates into a

470 significant bias in many published STMs and most historical data sets relating to stem taper.

471 Our results show that STMs based on censored data will overestimate main stem volume for the

472 general population of trees, with the magnitude of the bias dependent upon what proportion of

473 trees in the general population are 'irregular' in form. If STMs are used to compute stem

474 volumes that are later extrapolated to whole-tree mass estimates, e.g., biomass expansion 
475 factors (Lehtonen et al. 2004, Jalkanen et al. 2005, Skovsgaard and Nord-Larsen 2012, Domke 476 et al. 2012), censoring bias could significantly skew forest biomass and carbon stock inventories 477 estimated from stem volume. Overestimation of main stem volume would presumably then 478 cause over-estimation in whole-tree biomass (Lehtonen et al. 2004). Biomass expansion 479 factors should be particularly sensitive to the relative proportion of volume in the main stem 480 versus the branches (MacFarlane 2011).

Given the high degree of plasticity in tree morphology, despite species-specific constraints on branching architecture (Dardick et al. 2013, MacFarlane 2015), and given 483 significant influences of silvicultural practices (e.g., thinning, Assmann 1970) and environment 484 (e.g., frost, bud moths, Kerr and Boswell 2001) on tree form, it is not unreasonable to suppose 485 that the idealized trees that modelers seek for STM development may not actually represent the 486 typical tree encountered during forest inventory. This means that for STMs fit with exclusions to 487 be applied without bias, trees would need to be categorized as belonging to, or not belonging to, 488 the exclusion group. We recommend that future studies should eschew exclusion criteria and 489 expand taper data sets to include so-called irregular trees. This would allow model developers to either fit a general STM to trees of all forms, or take an approach, such as the one described 491 here, to categorize form differences between different types of trees. Minimally, one could fit the 492 taper model to a population of "included" vs. "excluded" trees and report the difference.

\section{Acknowledgements}

The authors would like to thank the Michigan Department of Natural Resources (MDNR)

496 for contributing significant resources to amassing the data used in this study. In particular Doug 497 Heym, who has been an advocate for innovation in forest inventory in Michigan. Part of DWM's 498 time was supported with funds from Michigan AgBioResearch, through the USDA National 
499 Institute of Food and Agriculture, with additional support from the MDNR. A portion of ARW's

500 time was supported by the Maine Agricultural and Forest Experimental Station. Both DWM and

501 ARW received support from the USDA Forest Service, Northern Research Station, Forest

502 Inventory and Analysis Program, NRS-05 (FIA).

503

\section{References}

504 Adu-Bredu, S., Bi. A.F.T., Bouillet, J-P., Me, M.K., Kyei, S.Y., and Saint-Andre, L. 2008. An

505 explicit stem profile model for forked and un-forked teak (Tectona grandis) trees in West Africa.

506 Forest Ecology and Management, 255: 2189-2203.

507 Assmann, E. 1970. The Principles of Forest Yield Study. Pergamon Press, Oxford, U.K. 506. p.

508 Barrio Anta, M., Diéguez-Aranda, U., Castedo-Dorado, F., González, J.G.A., and von Gadow, K. 509 2007. Merchantable volume system for pedunculate oak in northwestern Spain. Annals of 510 Forest Science, Volume 64 (5): 511-520.

511 Barthelemy, D. and Caraglio, Y. 2007. Plant architecture: a dynamic, multilevel and

512 comprehensive approach to plant form, structure and ontogeny. Ann. Bot. 99, 375-407.

513 Bebber, D.P., Thomas, S.C., Cole, W.G., Balsillie, D. 2004. Diameter increment in mature

514 eastern white pine Pinus strobus L. following partial harvest of old-growth stands in Ontario,

515 Canada. Trees, 18:29-34.

516 Bravo-Oviedo A, del Río M, Calama R, Valentine HT. 2014. New approaches to modelling

517 cross-sectional area to height allometry in four Mediterranean pine species. Forestry, 87:399518406.

519 Burkhart, H. E. 1977. Cubic foot volume of loblolly pine to any merchantable top limit. Southern 520 Journal of Applied Forestry, 1: 7-9. 
521 Burkhart, H.E.and Walton, S.B. 1985. Incorporating crown ratio into taper equations for loblolly 522 pine trees. Forest Science, 31, $478-484$.

523 Cao, Q.V., and J. Wang. 2011. Calibrating fixed- and mixed-effects taper equations. Forest 524 Ecology and Management, 262: 671-673.

525 Chave, J., Réjou-Méchain, M., Búrquez, A., Chidumayo, E., Colgan, M.S., Delitti, W.B.C, 526 Duque, A., Eid, T., Fearside, P.M., Goodman, R.C., Henry, M., Martínez-Yrízar, A., Mugasha, 527 W.A., Muller-Landau, H.C., Mencuccini, M., Nelson, B.W., Ngomanda, A., Nogueira, A., Ortiz528 Malavassi, E., Pélissier, R., Ploton, P., Ryan, C.M., Saldarriaga, J.G., Vieilledent, G. 2014. 529 Improved allometric models to estimate the aboveground biomass of tropical trees. Global 530 Change Biology, 20: 3177-3190.

531 Clark, Alexander, III; Souter, Ray A.; Schlaegel, Bryce E. 1991. Stem Profile for Southern 532 Equations for Southern Tree Species. Res. Pap. SE-282. Asheville, NC: U.S. Department of 533 Agriculture, Forest Service, Southeastern Forest Experiment Station. 117 p.

535 Abbott, A., and Scorza, R. 2013. PpeTAC1 promotes the horizontal growth of branches in peach 536 trees and is a member of a functionally conserved gene family found in diverse plants species. 537 The Plant Journal, 75: 618-630.

538 Domke, G.M., Woodall, C.W., Smith, J.E., Westfall, J.A., McRoberts, R.E., 2012. Consequences 539 of alternative tree-level biomass estimation procedures on U.S. forest carbon stock estimates. 540 Forest Ecology and Management, 270, 108-116.

541 Ducey, M.J. 2012. Evergreenness and wood density predict height-diameter scaling in trees of 542 the northeastern United States. Forest Ecology and Management, 279, 21-26. 
543 Forslund, R.R. 1982. A geometrical volume model based on the location of the centre of 544 gravity of the bole. Canadian Journal of Forest Research, 12: 215-221.

545 Neilsen, W.A., and Gerrand, A.M. 1999. Growth and branching habit of Eucalyptus nitens at 546 different spacing and the effect on final crop selection. Forest Ecology and Management, 123 : $547 \quad 217-229$.

548 Gevorkiantz, S.R., and Olsen, L.P. 1955. Composite volume tables for timber and their 549 application in the Lake States. Technical Bulletin No. 1104, Jan., 1955, USDA, Washington, 550 D.C.

551 Gomat, H.Y., Deleporte P., Moukini R., Mialounguila G., Ognouabi N., Saya A.R., Vigneron P., 552 Saint André L.. 2011. What factors influence the stem taper of Eucalyptus: Growth, 553 environmental conditions, or genetics? Annals of Forest Science, 68: p. 109-120.

554 Jalkanen, A., Mäkipääb, R., Ståhl, Göran, Lehtonen, 2005. A. and Petersson, H. Estimation of 555 the biomass stock of trees in Sweden: comparison of biomass equations and age-dependent 556 biomass expansion factors. Annals or Forest Science, 62: 845-851.

557 Jordan, L., Souter, R., Parresol, B., and Daniels, R.F. 2006. Application of the algebraic 558 difference approach for developing self-referencing specific gravity and biomass equations. 559 Forest Science, 52: 81-92.

560 Kerr, G.and Boswell , R.C. 2001 The influence of spring frosts, ash bud moth (Prays fraxinella) 561 and site on forking of young ash (Fraxinus excelsior) in southern Britain. Forestry. 74, 29 - 40.

562 Kozak, A, Munro, D.D. and Smith, J. H. G. 1969. Taper functionsa and their application in forest 563 inventory. Forestry Chronicle, 45: 1-6. 
564 Kublin E, Breidenbach (2013) TapeR_Flexible tree taper curves based on semiparametric

565 mixed models. R-package version 0.3.0. Available on CRAN: http://cran.r-

566 project.org/web/packages/TapeR/.

567 Lehtonen, A., Ciencialia, E., Tatarinov, F., and Mäkipää, R. 2007. Uncertainty estimation of 568 biomass expansion factors for Norway spruce in the Czech Republic. Annals of Forest Science, 569 64: 133-140.

570 MacFarlane, D.W. 2010. Predicting branch to bole volume scaling relationships from varying 571 centroids of tree bole volume. Canadian Journal of Forest Research, 40: 2278-2289.

572 MacFarlane, D.W. 2015. A generalized tree component biomass model derived from principles 573 of variable allometry. Forest Ecology and Management, 354: 43-55.

574 MacFarlane, D.W. 2011. Allometric scaling of branch volume in hardwood trees in Michigan, 575 USA: implications for improvements in above-ground forest carbon biomass inventories. Forest 576 Science, 57: 451- 459.

577 MacFarlane, D.W., Kuyah, S., Mulia, R., Dietz, J., Muthuri, C., and Van Noordwijk, M. 2014. 578 Evaluating a non-destructive method for calibrating tree biomass equations derived from tree 579 branching architecture. Trees, 28: 807-817.

580 Max, T.A. and Burkhart, H.E. 1976. Segmented polynomial regression applied to taper 581 equations. Forest Science, 22, 283-289.

582 McTague, J.P., and Bailey, R.L. 1987. Simultaneous total and merchantable volume equations 583 and a compatible taper function for loblolly pine. Canadian Journal of Forest Research, 17: 8758492. 
585 MDNR. 2013. Product Standards and Cruising Manual. IC4057, Michigan Department of Natural 586 Resources, Forest Resources Division. 07/03/2013. 44 p.

587 Muhairwe, C.K. 1994. Tree form and taper variation over time for interior lodgepole pine.

588 Canadian Journal of Forest Research, 24:1904-1913.

589 Muhairwe, C.K., LeMay, V.M., and Kozak, A. 1994. Effects of adding tree, stand, and site 590 variables to Kozak's variable-exponent taper equation. Canadian Journal of Forest Research, $591 \quad 24: 252-259$.

592 Newnham, R.M. 1992. Variable form taper functions for four Alberta tree species. Canadian 593 Journal of Forest Research, 22: 210-223.

594 Niklas, K.J. 1995. Size-dependent allometry of tree height, diameter and trunk-taper. Annals of 595 Botany, 75: 217-227.

596 Ozcelik, R. 2008. Comparison of formulae for estimating tree bole volumes of Pinus sylvestris.

597 Scandinavian Journal of Forest Research, 23(5): 412-418.

598 Pinheiro J, Bates D, DebRoy S, Sarkar D and R Core Team (2015). nlme: Linear and nonlinear 599 mixed effects models. R package version 3.1-122, http://CRAN.R-project.org/package=nlme.

600 Paradis E., Claude J. \& Strimmer K. 2004. APE: analyses of phylogenetics and evolution in R 601 language. Bioinformatics, 20: 289-290.

602 R Development Core Team. 2015. R: a language and environment for statistical computing. R 603 Foundation for Statistical Computing, Vienna, Austria.

604 Sabatia, C.O., and Burkhart, H. E. 2015. On the use of upper stem diameters to localize a 605 segmented taper equation to new trees. Forest Science, 61: 411-423. 
606 Skovsgaard, J.P. and Nord-Larsen, T. 2012. Biomass, basic density and biomass expansion 607 factor functions for European beech (Fagus sylvatica L.) in Denmark. European Journal of 608 Forest Research, 131:1035-1053.

609 Stiell W.M. 1979. Releasing unweevilled white pine to ensure first log quality of final crop. 610 Forestry Chronicle, 55:142-143.

611 Sherill, J.R. Mullin, T.R., Bullock, B.P., McKeand, S.E. and Purnell, R.C. 2004. Forest Genetics 612 and Tree Breeding in the Age of Genomics: Progress and Future, IUFRO Joint Conference of 613 Division 2, Conference Proceedings. 1-5 November 2004, editied by B. Li and S.E. McKeand, 614 Volume: Pp. 457

615 Venables, W. N. and Ripley, B. D. 2002. Modern Applied Statistics with S (Fourth Edition). New 616 York: Springer-Verlag.

617 Valentine, H.T., and Gregoire, T.G. 2001. A switching model of bole taper. Canadian Journal of 618 Forest Research, 31: 1400-1409.

619 Ver Planck N.R., MacFarlane, D.W. 2015. A vertically integrated whole-tree biomass Model. 620 Trees, 29: 449-460.

621 Ver Planck N.R., MacFarlane, D.W. 2014. Modelling vertical allocation of tree stem and branch 622 volume for hardwoods. Forestry; 00, 1-16 doi:10.1093/forestry/cpu007.

623 Wilson, B.F. 2000. Apical control of branch growth and angle in woody plants. American Journal 624 of Botany 87(5): 601-607.

625 Xiong, J.S., Isik, F., McKeand, S.E., and Whetten. R.W. 2010. Genetic variation of stem forking 626 in loblolly pine. Forest Science, 56(5):429-436. 
627 Zakrzewski, W.T. 2011 Estimating wood volume of the stem and branches of sugar maple (Acer

628 saccharum marsh.) using a stem profile model with implicit height. Forest Science, 57, 117-133.

629 Zakrzewski. W.T., and Duchesne, I. 2012. Stem biomass model for jack pine (Pinus banksiana

630 Lamb.) in Ontario. Forest Ecology and Management, 279:112-120, 2012.

631

632

633

634

635

636

637

638

639

640

641

642

643

644

645

646

647

648

649

650 
Table 1. Study tree attributes, listed by species.

\begin{tabular}{|c|c|c|c|c|}
\hline species & $\begin{array}{c}\# \\
\text { stands }\end{array}$ & \# trees & $\begin{array}{c}\text { mean DBH }(\mathrm{cm}) \\
{[\mathrm{sd}, \min , \max ]}\end{array}$ & $\begin{array}{l}\text { mean Height }(\mathrm{m}) \\
{[\mathrm{sd}, \min , \max ]}\end{array}$ \\
\hline Abies balsamea & 1 & 37 & $20.7[5.7,11.9,39.4]$ & $16.3[3.5,11.6,25.6]$ \\
\hline Picea glauca & 1 & 2 & $35.8[14.3,18.0,46.7]$ & $20.5[6.2,12.9,25.2]$ \\
\hline Pinus banksiana & 2 & 152 & $20.6[5.7,11.7,41.4]$ & $13.2[2.3,6.9,20.1]$ \\
\hline Pinus resinosa & 2 & 198 & $35.2[4.4,17.5,48.3]$ & $22.2[1.9,12.7,26.5]$ \\
\hline Pinus strobus & 5 & 56 & $51.9[25.7,14.7,101.6]$ & $23.8[7.0,12.0,34.0]$ \\
\hline All Needle-leaved & 7 & 445 & $30.3[14.8,11.7,101.6]$ & $19.2[5.5,6.9,34.0]$ \\
\hline Acer rubrum & 14 & 219 & $33.0[12.2,11.9,69.6]$ & $21.6[3.7,8.9,32.1]$ \\
\hline Acer saccharhinum & 1 & 2 & $37.0[6.6,30.2,43.2]$ & $24.9[1.5,23.3,26.2]$ \\
\hline Acer saccharum & 14 & 397 & $35.3[11.8,11.9,73.7]$ & $23.7[3.2,13.1,31.7]$ \\
\hline Amelenchier arborea & 1 & 1 & $34.3[-, 34.3,34.3]$ & $23.4[-, 23.4,23.4]$ \\
\hline Betula alleghaniensis & 4 & 46 & $33.5[12.2,16.5,63.8]$ & $20.7[2.9,12.0,27.5]$ \\
\hline Betula papyrifera & 6 & 70 & $27.3[9.1,12.4,57.4]$ & $21.3[2.8,13.2,26.2]$ \\
\hline Fagus grandifolia & 7 & 96 & $32.7[12.0,11.7,57.2]$ & $20.8[3.9,12.3,30.4]$ \\
\hline Fraxinus americana & 9 & 80 & $38.4[14.7,15.0,77.7]$ & $26.5[3.9,16.6,34.5]$ \\
\hline Ostrya virginiana & 1 & 2 & $24.4[1.7,22.9,26.2]$ & $19.2[0.3,18.9,19.6]$ \\
\hline Populus balsamifera & 1 & 2 & $30.6[3.6,27.2,34.3]$ & $24.0[1.3,22.8,25.3]$ \\
\hline $\begin{array}{l}\text { Populus grandidentata } \\
\text { and P. tremuloides }{ }^{1}\end{array}$ & 5 & 113 & $29.0[7.6,14.7,54.6]$ & $23.5[3.0,15,31.7]$ \\
\hline Prunus serotina & 9 & 36 & $30.7[7.2,15.2,43.9]$ & $22.1[3.3,11.2,26.7]$ \\
\hline Quercus alba & 4 & 60 & $35.7[9.2,11.9,58.7]$ & $21.8[3.2,7.8,25.7]$ \\
\hline Quercus ellipsoidalis & 3 & 9 & $34.2[6.6,23.4,44.7]$ & $16.7[3.1,12.6,22.9]$ \\
\hline Quercus rubra & 5 & 112 & $33.5[9.2,13.2,56.9]$ & $24.7[3.6,14.8,32.4]$ \\
\hline Tilia americana & 9 & 138 & $37.2[9.8,15.2,78.5]$ & $24.3[3.2,13.2,30.2]$ \\
\hline All broad-leaved & 29 & 1383 & $32.9[11.4,11.7,78.5]$ & $23.2[3.7,7.8,34.5]$ \\
\hline All trees & 31 & 1828 & $32.3[7.1,11.7,101.6]$ & $21.6[4.7,6.9,34.5]$ \\
\hline
\end{tabular}

${ }^{1}$ these two Populus species were not consistently differentiated in the field so they were combined. 
Table 2. Study trees classified into Large Branch Types (LBT) and Merchantable Branch-Types (MBT), listed by species.

\begin{tabular}{|c|c|c|c|c|c|c|c|c|c|}
\hline \multirow[b]{2}{*}{ species } & \multirow{2}{*}{$\begin{array}{c}\# \\
\text { trees }\end{array}$} & \multicolumn{2}{|c|}{$\begin{array}{c}\text { Large } \\
\text { Branch Type } \\
\text { (LBT) }\end{array}$} & \multicolumn{2}{|c|}{$\%$ in LBT } & \multicolumn{4}{|c|}{$\begin{array}{c}\text { Merchantable Branch } \\
\text { Type (MBT) }\end{array}$} \\
\hline & & 0 & 1 & 0 & 1 & $0-0$ & $0-1$ & $1-0$ & $1-1$ \\
\hline Abies balsamea & 37 & 37 & - & $100 \%$ & $0 \%$ & 37 & - & - & - \\
\hline Picea glauca & 2 & 2 & - & $100 \%$ & $0 \%$ & 2 & - & - & - \\
\hline Pinus banksiana & 152 & 149 & 3 & $98 \%$ & $2 \%$ & 149 & - & 3 & - \\
\hline Pinus resinosa & 198 & 194 & 4 & $98 \%$ & $2 \%$ & 194 & - & 3 & 1 \\
\hline Pinus strobus & 56 & 48 & 8 & $86 \%$ & $14 \%$ & 48 & - & 2 & 6 \\
\hline All conifers & 445 & 430 & 15 & $97 \%$ & $3 \%$ & 430 & - & 8 & 7 \\
\hline Acer rubrum & 219 & 127 & 92 & $58 \%$ & $42 \%$ & 127 & 1 & 69 & 22 \\
\hline Acer saccharhinum & 2 & 1 & 1 & $50 \%$ & $50 \%$ & 1 & - & 1 & - \\
\hline Acer saccharum & 397 & 161 & 236 & $41 \%$ & $59 \%$ & 161 & - & 210 & 26 \\
\hline Amelenchier arborea & 1 & - & 1 & $0 \%$ & $100 \%$ & - & - & 1 & - \\
\hline Betula alleghaniensis & 46 & 18 & 28 & $39 \%$ & $61 \%$ & 18 & 1 & 20 & 7 \\
\hline Betula papyrifera & 70 & 47 & 23 & $67 \%$ & $33 \%$ & 47 & 1 & 19 & 3 \\
\hline Fagus grandifolia & 96 & 63 & 33 & $66 \%$ & $34 \%$ & 63 & 1 & 28 & 4 \\
\hline Fraxinus americana & 80 & 36 & 44 & $45 \%$ & $55 \%$ & 36 & - & 27 & 17 \\
\hline Ostrya virginiana & 2 & 2 & - & $100 \%$ & $0 \%$ & 2 & - & - & - \\
\hline Populus balsamifera & 2 & 2 & - & $100 \%$ & $0 \%$ & 2 & - & - & - \\
\hline \multirow[t]{2}{*}{$\begin{array}{l}\text { Populus grandidentata } \\
\text { and P. tremuloides }{ }^{1}\end{array}$} & & & & & & & - & & - \\
\hline & 113 & 102 & 11 & $90 \%$ & $10 \%$ & 102 & & 11 & \\
\hline Prunus serotina & 36 & 18 & 18 & $50 \%$ & $50 \%$ & 18 & - & 17 & 1 \\
\hline Quercus alba & 60 & 12 & 48 & $20 \%$ & $80 \%$ & 12 & - & 38 & 10 \\
\hline Quercus ellipsoidalis & 9 & 7 & 2 & $78 \%$ & $22 \%$ & 7 & - & 1 & 1 \\
\hline Quercus rubra & 112 & 40 & 72 & $36 \%$ & $64 \%$ & 40 & - & 52 & 20 \\
\hline Tilia americana & 138 & 80 & 58 & $58 \%$ & $42 \%$ & 80 & 1 & 49 & 8 \\
\hline All hardwoods & 1383 & 716 & 667 & $52 \%$ & $48 \%$ & 716 & 5 & 543 & 119 \\
\hline All trees & 1828 & 1146 & 682 & $63 \%$ & $37 \%$ & 1146 & 5 & 551 & 126 \\
\hline
\end{tabular}

${ }^{1}$ these two Populus species were not consistently differentiated in the field so they were combined. 
Table 3. Study trees classified into Merchantable Form Types (MFT), listed by species.

\begin{tabular}{|c|c|c|c|c|c|c|c|c|c|c|c|}
\hline \multirow[b]{2}{*}{ species } & \multirow[b]{2}{*}{ \# trees } & \multicolumn{10}{|c|}{ Merchantable Form Type (MFT) } \\
\hline & & $0-0-0-0$ & $0-1-0-0$ & $0-1-1-0$ & $0-1-1-1$ & $1-0-0-0$ & $1-0-1-0$ & $1-1-0-0$ & $1-1-0-1$ & $1-1-1-0$ & $1-1-1-1$ \\
\hline Abies balsamea & 37 & - & - & - & - & 36 & - & 1 & - & - & - \\
\hline Picea glauca & 2 & - & - & - & - & 1 & - & 1 & - & - & - \\
\hline Pinus banksiana & 152 & 1 & - & - & - & 126 & - & 22 & - & 3 & - \\
\hline Pinus resinosa & 198 & - & - & - & - & 75 & 1 & 119 & - & 2 & 1 \\
\hline Pinus strobus & 56 & - & 16 & - & 1 & 16 & - & 16 & - & 2 & 5 \\
\hline All needle-leaved & 445 & 1 & 16 & - & 1 & 254 & 1 & 159 & - & 7 & 6 \\
\hline Acer rubrum & 219 & - & - & 1 & 1 & 67 & 16 & 60 & 1 & 52 & 21 \\
\hline Acer saccharhinum & 2 & - & - & - & - & - & - & 1 & - & 1 & - \\
\hline Acer saccharum & 397 & 1 & 1 & 1 & 2 & 94 & 26 & 65 & - & 183 & 24 \\
\hline Amelenchier arborea & 1 & - & - & - & - & - & - & - & - & 1 & - \\
\hline Betula alleghaniensis & 46 & - & - & - & 4 & 9 & - & 9 & 1 & 20 & 3 \\
\hline Betula papyrifera & 70 & - & - & - & - & 25 & 1 & 22 & 1 & 18 & 3 \\
\hline Fagus grandifolia & 96 & - & 8 & 1 & - & 33 & 2 & 22 & 1 & 25 & 4 \\
\hline Fraxinus americana & 80 & - & - & - & - & 11 & 2 & 25 & - & 25 & 17 \\
\hline Ostrya virginiana & 2 & - & - & - & - & 2 & - & - & - & - & - \\
\hline $\begin{array}{l}\text { Populus } \\
\text { grandidentata and } P ._{\text {tremuloides }^{1}}\end{array}$ & 113 & - & 5 & 1 & - & 50 & 1 & 47 & - & 9 & - \\
\hline Populus balsamifera & 2 & - & - & - & - & 1 & - & 1 & - & - & - \\
\hline Prunus serotina & 36 & - & - & - & - & 9 & 3 & 9 & - & 14 & 1 \\
\hline Quercus alba & 60 & - & - & 1 & - & 6 & 1 & 6 & - & 36 & 10 \\
\hline Quercus ellipsoidalis & 9 & - & - & - & - & 2 & - & 5 & - & 1 & 1 \\
\hline Quercus rubra & 112 & - & - & - & 1 & 17 & - & 23 & - & 52 & 19 \\
\hline Tilia americana & 138 & - & 2 & 2 & 1 & 21 & 2 & 57 & 1 & 45 & 7 \\
\hline All broad-leaved & 1383 & 1 & 16 & 7 & 9 & 347 & 54 & 352 & 5 & 482 & 110 \\
\hline All trees & 1828 & 2 & 32 & 7 & 10 & 601 & 55 & 511 & 5 & 489 & 116 \\
\hline$\%$ trees & & $0.1 \%$ & $1.8 \%$ & $0.4 \%$ & $0.5 \%$ & $32.9 \%$ & $3.0 \%$ & $28.0 \%$ & $0.3 \%$ & $26.8 \%$ & $6.3 \%$ \\
\hline
\end{tabular}

${ }^{1}$ these two Populus species were not consistently differentiated in the field so they were combined. 
Table 4. Model fit statistics for the standard Max and Burkhart (1976) taper model with two free joining points (eq. 1) and a $\mathrm{DBH}$-segmented version that fixes one joining point at the mean relative breast height for the population (eq. 2).

\begin{tabular}{lllllll}
\hline Model & df & AIC & BIC & log.lik. & like.ratio & p-value \\
eq. 1 & 9 & -16203 & -16133.54 & 8110.775 & & \\
eq. 2 & 8 & -26587 & -26525.39 & 13301.807 & 10382.07 & $<0.0001$ \\
\hline
\end{tabular}


Table 5. Fit statistics using the Max and Burkhart (1976)

taper model with various random effects on eq. 2

coefficients. The best model is presented in bold.

\begin{tabular}{llll}
\hline Coef. & AIC & BIC & LogLik \\
$\beta_{1}$ & -16980 & -16918 & 8498 \\
$\beta_{2}$ & -16647 & -16585 & 8331 \\
$\beta_{3}$ & \multicolumn{3}{c}{ below step halving factor } \\
$\beta_{4}$ & -26587 & -26525 & 13301 \\
$\alpha_{1}$ & \multicolumn{3}{c}{ below step halving factor } \\
$\beta_{1}+\beta_{4}$ & -29392 & -29299 & 14708 \\
$\beta_{2}+\beta_{4}$ & -30395 & -30302 & 15209 \\
$\beta_{1}+\beta_{2}+\beta_{4}$ & -33034 & -32894 & 16535 \\
\hline
\end{tabular}


Table 6. Model coefficients with standard error in parentheses and fit statistics for eq. 3 (ME = mean error, $\mathrm{MAE}=$ mean absolute error, $\mathrm{RMSE}=$ root mean square error $).$ Abies balsamea with Merchantable Form Type (MFT) 0-0-0-0 was used as the reference level (Intercept) for comparing random effects of the other species and MFTs to.

\begin{tabular}{|c|c|c|c|}
\hline & ME & MAE & RSME \\
\hline eq. 3 & 0.0005 & 0.0726 & 0.1419 \\
\hline \multirow[t]{4}{*}{ Fixed effects } & $\beta_{1}$ & $\beta_{2}$ & $\beta_{3}$ \\
\hline & $-3.9846(0.2055)$ & $2.0105(0.1242)$ & $-1.865(0.1093)$ \\
\hline & $\beta_{4}$ & $\alpha_{1}$ & $\alpha_{2}$ \\
\hline & $138.4753(7.7222)$ & $0.7001(0.0124)$ & $0.0673(0.0001)$ \\
\hline \multicolumn{4}{|c|}{ Random effects } \\
\hline & $\mu_{1}$ & $\mu_{2}$ & $\mu_{4}$ \\
\hline Intercept & $0.0710(0.1927)$ & $-0.0785(0.1903)$ & $15.0346(90.9481)$ \\
\hline MFT & $\mu_{1}$ & $\mu_{2}$ & $\mu_{4}$ \\
\hline $0-0-0-0$ & - & - & - \\
\hline $0-1-0-0$ & $0.2305(0.1915)$ & $-0.2163(0.1896)$ & 6.7301 (91.1553) \\
\hline $0-1-1-0$ & $-0.0294(0.2079)$ & $0.0192(0.2059)$ & $40.2638(99.1691)$ \\
\hline $0-1-1-1$ & $-0.1827(0.2026)$ & $0.1888(0.2005)$ & $-80.5889(96.3921)$ \\
\hline $1-0-0-0$ & $0.2306(0.1833)$ & $-0.2228(0.1815)$ & $45.3814(87.4401)$ \\
\hline $1-0-1-0$ & $-0.1714(0.1877)$ & $0.1777(0.1858)$ & $-13.1429(89.4219)$ \\
\hline $1-1-0-0$ & $0.1748(0.1837)$ & $-0.1652(0.1819)$ & $11.8544(87.6034)$ \\
\hline $1-1-0-1$ & $0.3186(0.2189)$ & $-0.3000(0.2166)$ & 1.1661 (104.0487) \\
\hline $1-1-1-0$ & $0.0183(0.1837)$ & $-0.0147(0.1819)$ & $-10.3019(87.6118)$ \\
\hline $1-1-1-1$ & $-0.2473(0.1847)$ & $0.2461(0.1830)$ & $-14.9249(88.1492)$ \\
\hline
\end{tabular}




\begin{tabular}{|c|c|c|c|}
\hline species & $\mu_{1}$ & $\mu_{2}$ & $\mu_{4}$ \\
\hline Abies balsamea & - & - & - \\
\hline Picea glauca & $-0.1740(0.1858)$ & $0.1781(0.1840)$ & $-3.7965(88.8311)$ \\
\hline Pinus banksiana & $-0.1447(0.0807)$ & $0.1364(0.0788)$ & $-46.5734(34.6997)$ \\
\hline Pinus resinosa & $-0.0192(0.1077)$ & $0.0192(0.1032)$ & $-59.9879(41.3147)$ \\
\hline Pinus strobus & $-0.3074(0.0825)$ & $0.312(0.0806)$ & $-61.4255(35.8098)$ \\
\hline Acer rubrum & $-0.3478(0.0585)$ & $0.3472(0.0576)$ & $-52.9227(26.8991)$ \\
\hline Acer saccharhinum & $-0.5638(0.1950)$ & $0.5741(0.1930)$ & $-185.2351(92.4421)$ \\
\hline Acer saccharum & $-0.2317(0.0564)$ & $0.2271(0.0557)$ & $-9.9501(26.1222)$ \\
\hline Amelenchier arborea & $-0.4268(0.2638)$ & $0.4318(0.2613)$ & $-154.4622(125.8714)$ \\
\hline Betula alleghaniensis & $-0.3238(0.0788)$ & $0.3097(0.0775)$ & 75.5961 (35.7510) \\
\hline Betula papyrifera & $-0.0152(0.0655)$ & $0.0189(0.0646)$ & 7.9239 (30.1749) \\
\hline Fagus grandifolia & $-0.1753(0.0681)$ & $0.1694(0.0670)$ & $17.6663(30.9635)$ \\
\hline Fraxinus americana & $-0.0883(0.0655)$ & $0.0946(0.0645)$ & $-24.8026(30.0410)$ \\
\hline Ostrya virginiana & $-0.2719(0.1916)$ & $0.2549(0.1897)$ & 211.1978 (91.2025) \\
\hline Populus balsamifera & $-0.0299(0.1858)$ & $0.0458(0.1840)$ & $-116.2716(88.8311)$ \\
\hline $\begin{array}{l}\text { Populus grandidentata } \\
\text { and P. tremuloides }{ }^{1}\end{array}$ & $0.1431(0.0545)$ & $-0.1294(0.0538)$ & $-67.1723(25.5528)$ \\
\hline Prunus serotina & $-0.0344(0.0764)$ & $0.0392(0.0752)$ & $-58.874(34.9918)$ \\
\hline Quercus alba & $-0.3668(0.0708)$ & $0.3648(0.0697)$ & $6.1543(32.5058)$ \\
\hline Quercus ellipsoidalis & $-0.1890(0.1145)$ & $0.1716(0.1126)$ & $-16.5648(52.2819)$ \\
\hline Quercus rubra & $-0.1243(0.0650)$ & $0.1272(0.0640)$ & $16.3635(29.9453)$ \\
\hline Tilia americana & $-0.0098(0.0560)$ & $0.0230(0.0553)$ & $-38.9422(26.2258)$ \\
\hline
\end{tabular}




\section{Figure captions}

Figure 1. Relative components of variation in observed main stem outside bark volume from stem taper data from different grouping variables. Variance components are relative to tree to tree variation which describes $100 \%$ of the variation (variance component $=1$ ) in the data used to fit the model. (a) shows a case when form types are omitted and (b-d) show the contribution of adding LBT (Large Branch Types), MBT (Merchantable Branch Types) and MFT (Merchantable Form Types) as grouping variables.

Figure 2. A scatter plot of the relative cross-sectional area outside bark (relcob) at different relative height locations (relh), from 1828 trees of 21 species (light gray circles), with data from Quercus rubra (Quru) trees superimposed (dark gray circles). The predicted taper curves from $\mathrm{DBH}$-segmented polynomial stem taper model with variable random effects are shown for Quru for four different MFTs (Merchantable Form Types), representing a range of forms. The solid line is the fixed effects model for the entire population of trees, from which Quru trees of differing form diverge (eq. 3).

Figure 3. A scatter plot of the relative cross-sectional area outside bark (relcob) at different relative height locations (relh), with data from Acer saccharum (Acsa)(light gray circles) Tilia americana (Tiam) trees superimposed (asterisks). The predicted taper curves from DBHsegmented polynomial stem taper model with variable random effects are shown for Acsa and Tiam for two different MFTs (Merchantable Form Types): 1-0-0-0 and 1-0-1-0. The solid line is the fixed effects model for the entire population of trees, from which each diverges based on predicted random effects (eq. 3). 
Fig. 1

a

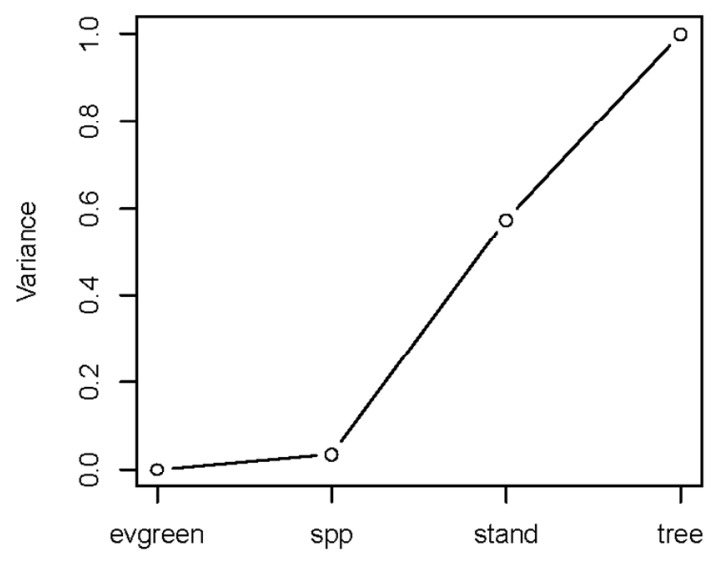

c

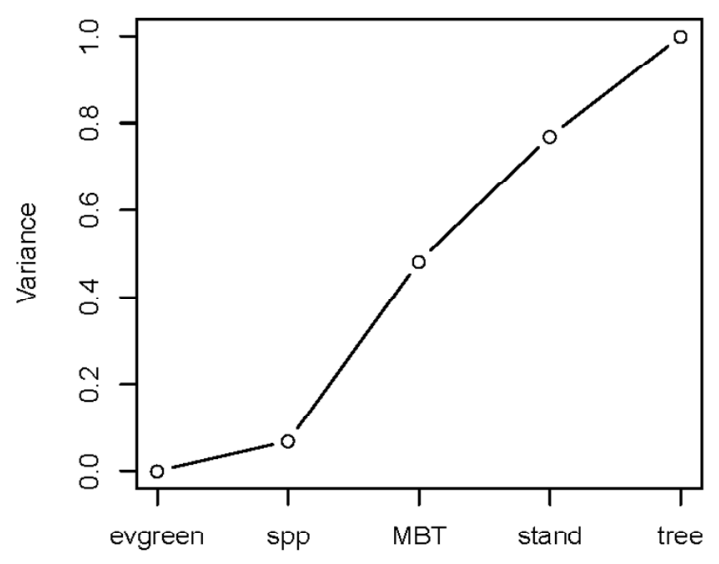

b

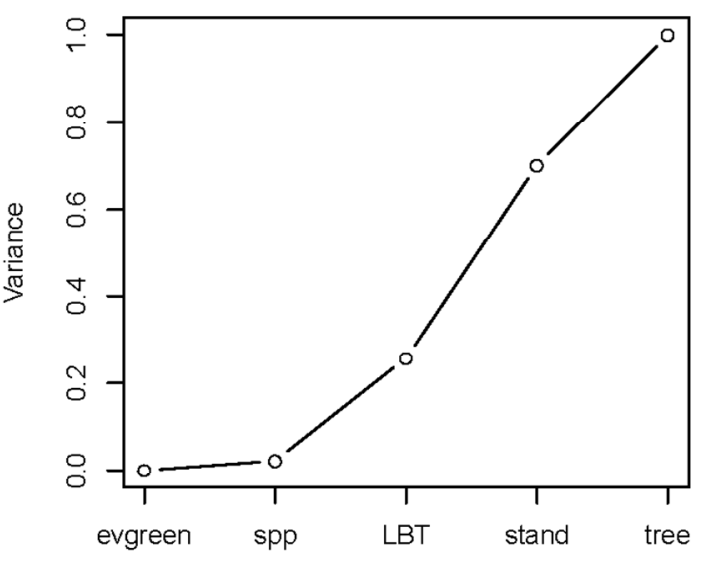

d

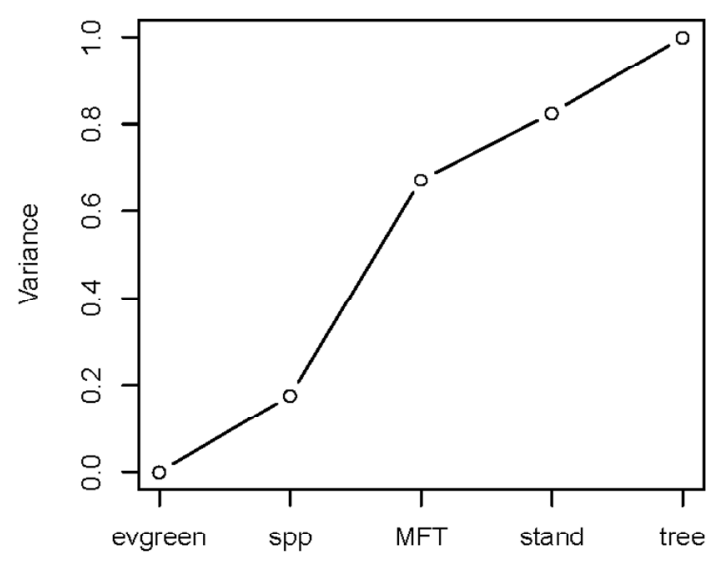


Fig. 2

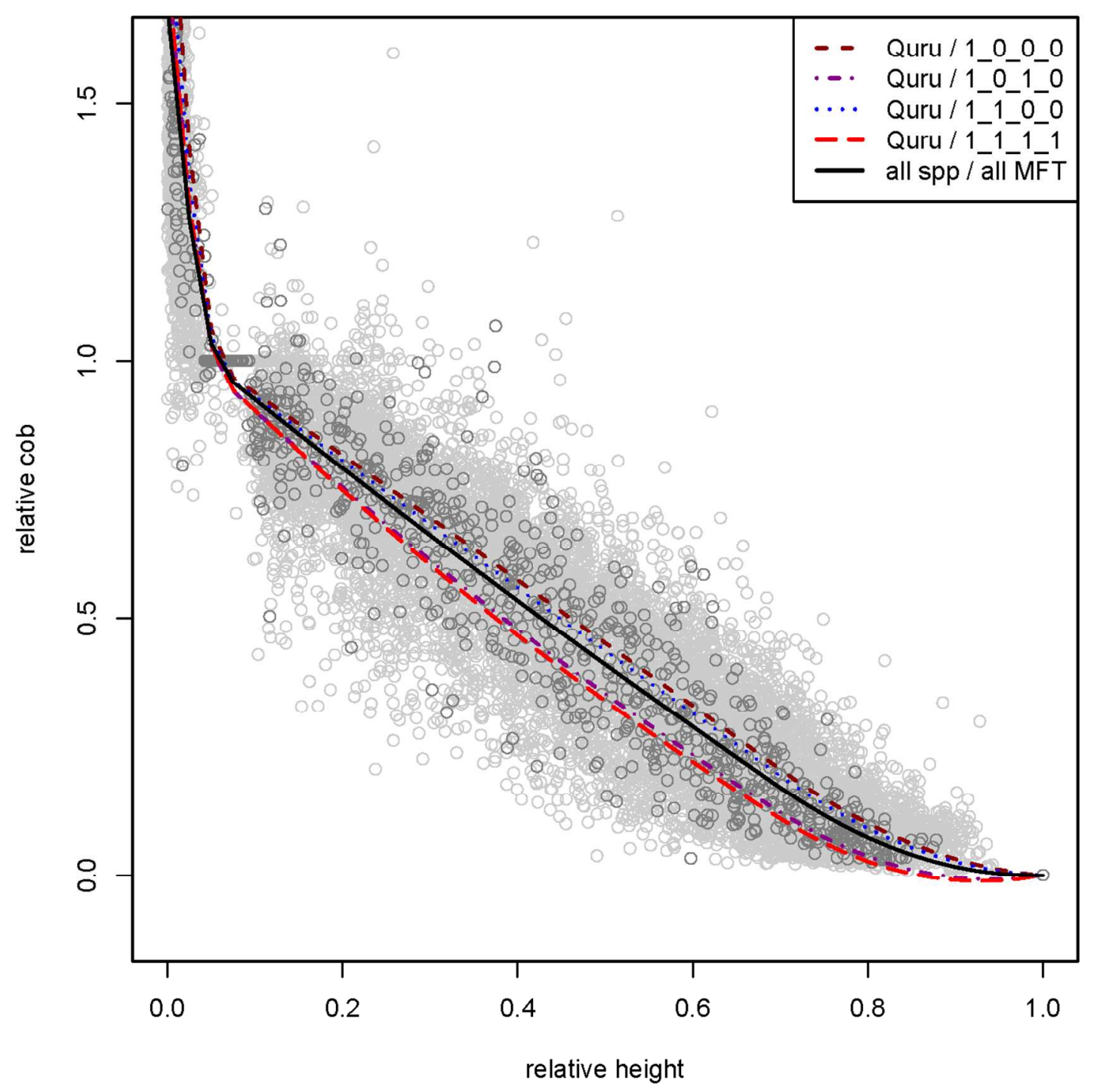


Fig. 3

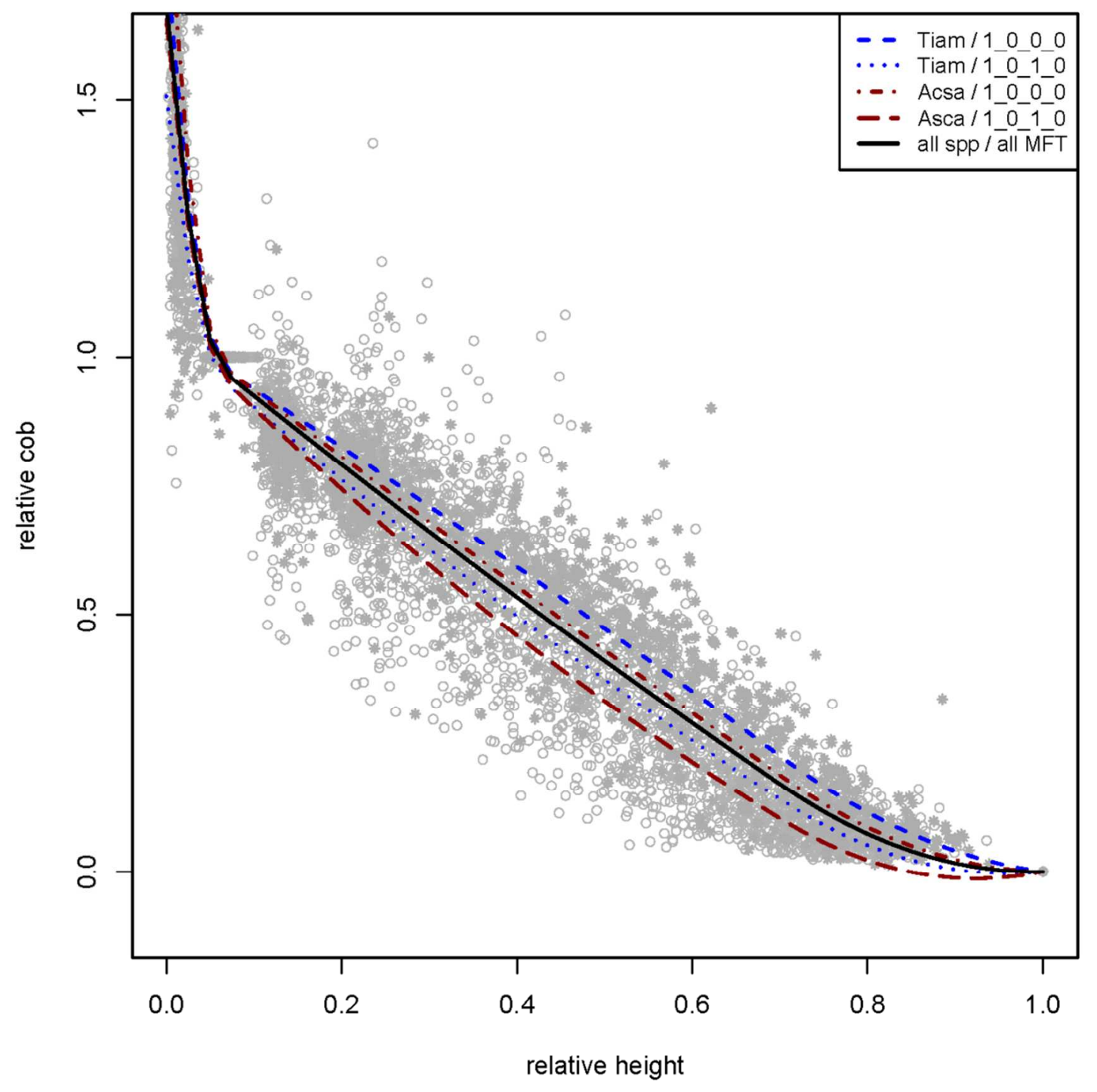

